\title{
Palma y el Congreso Constituyente de 1867
}

\author{
Carlos Alberto Pérez Garay \\ Universidad Ricardo Palma \\ charlyx333@hotmail.com
}

\section{Resumen}

El presente trabajo trata de mostrar la labor periodística de Palma y sus avatares en la prensa política durante el gobierno del presidente Mariano Ignacio Prado. Fiel a su estilo, satírico y burlón, el tradicionista describe la actuación de los diputados del Congreso Constituyente de 1867 en unas pequeñas Semblanzas, las cuales aparecieron por primera vez en el periódico La Campana. En ese sentido, ironía, sátira y humor serán los ingredientes que Palma utilizará con el propósito de divertir a su legión de lectores de la ciudad de Lima en los últimos años del período de la prosperidad falaz o era del guano.

Palabras clave: Ricardo Palma, La Campana, Semblanzas, Dictadura

\begin{abstract}
The present work tries to show the journalistic work of Palma and its avatars in the political press during the government of President Mariano Ignacio Prado. True to his style, satirical and mocking, the traditionist describes the performance of the deputies of the Constituent Congress of 1867, in a few small portraits, which appeared for the first time in the newspaper La Campana. In that sense, irony, satire and humor will be the ingredients that Palma will use for the purpose of amusing his legion of readers of the city of Lima in the last years of the deceased prosperity period or the guano age.
\end{abstract}

Keywords: Ricardo Palma, La Campana, Biography, Dictatorship 
Carlos Alberto Pérez Garay, Licenciado en Historia por la Universidad Nacional Mayor de San Marcos. Con estudios de maestría en la misma especialidad en dicha casa de estudios. Docente e investigador. Ha participado como ponente y conferencista en importantes eventos académicos en el país. Ejerce la docencia en la Universidad Ricardo Palma en el Programa de Estudios Básicos (PEB) y en la Facultad de Ciencias Económicas y Empresariales. Es especialista en temas de historia política, intelectual y literaria. Entre sus trabajos se encuentran numerosos artículos en revistas especializadas y un libro sobre el tradicionista: Liberalismo criollo. Ricardo Palma, ideología y política (1833-1919), publicado en Lima el 2015 por el Fondo Editorial de la Universidad Ricardo Palma. 


\section{La dictadura de Prado y la convocatoria a elecciones}

Después del glorioso Combate del Dos de Mayo, el coronel Mariano Ignacio Prado, en su afán de mantenerse en el mando, convocó a elecciones generales para elegir a un nuevo presidente constitucional y a un nuevo Congreso Constituyente, el 28 de julio de 1866. Ante esta convocatoria, surgieron numerosas candidaturas en Lima y en el interior de la Republica. Si bien Prado se presentaba como el principal favorito, la candidatura del coronel José Balta empezó a ir en aumento debido a la activa labor de sus simpatizantes, conllevando a una dura batalla electoral entre los partidarios del oficialismo y de la oposición.

Palma, que por ese año prestaba servicio en la Marina, empezó a mostrar simpatía por Balta. A pesar de formar parte de la burocracia estatal, comenzó a cuestionar, como muchos, los actos de la dictadura, en especial el decreto de convocatoria a elecciones a través de las paginas de El Constitucional, razón por la que fue dado de baja de la institución naval el 12 de octubre de 1866, siendo luego conducido a la cárcel de Casamatas en el Callao, en donde estuvo por espacio de tres meses para finalmente ser desterrado, en enero de 1867, a la República del Ecuador. Visiblemente afectado, su molestia e indignación contra el régimen se tornó mayor que antes. Sin embargo, el exilio ecuatoriano no duraría mucho tiempo.

Entre tanto, en el Perú sin ninguna oposición significativa, el proceso electoral había concluido en diciembre de 1866, resultando elegido presidente el coronel Mariano Ignacio Prado. Asimismo, fueron elegidos los representantes del nuevo Congreso Constituyente, el cual estaría compuesto por 94 diputados propietarios y 39 suplentes. Como en todas las elecciones, se modificaron ciertas normas electorales. Para votar se debía de presentar un documento de haber pagado la 
contribución personal: el único requisito. Además, podían ser elegidos los ciudadanos extranjeros, pero no podían participar ahora los religiosos. En efecto, en otros años, tuvimos personajes del clero de la talla de Javier de Luna Pizarro y Bartolomé Herrera, quienes se convirtieron en principales artífices de dos constituciones. Asimismo, de acuerdo a las disposiciones del decreto de elecciones, tampoco podían ser elegidos los vocales, jueces y prefectos.

Dicho Congreso iba a funcionar por un período de cien días hábiles. Improrrogables. Mientras durase la elaboración de la nueva carta magna debía regir la Constitución de 1856.

\section{Las sesiones legislativas del Congreso Constituyente de 1867}

El 15 de febrero de 1867 se instaló el Congreso Constituyente. Reunidos, en sesión plena, los representantes del Legislativo proclamaron a Prado como presidente provisional de la República. A partir de ese momento "se produjeron fricciones entre el Ejecutivo y el Congreso, pues éste no quería renunciar a su atribución fiscalizadora pese a que su misión era extraordinaria" (Gálvez, 2002: 158).

Habría que señalar que fue un Congreso integrado por una mayoría liberal: Fernando Casós y Celso Bambarén lo integraban. Se legislaron sobre diversos temas, los cuales, tras su debate y aprobación, lograron promulgarse. Entre estos temas, se promulgó la creación de un sistema parlamentario bicameral a partir de la constitución de 1856; la creación del cargo de Fiscal General Administrativo, en reemplazo del Fiscal de la Nación; el nombramiento de los vocales supremos por parte del Congreso; la prohibición del destierro y el confinamiento, salvo por declaración de sentencia judicial; etc. Sin embargo, el tema 
religioso estaba a la orden del día. El secretario de Gobierno, José María Químper, decretó la prohibición de toques de campanas de las iglesias y el transporte de los sacramentos, originando un gran malestar en los grupos conservadores (Pérez Garay, 2015: 170). Estos, desde el Parlamento, apoyaron toda noción y propuesta de ley a favor de los principios del clero, la autoridad y la defensa de la tradición. No obstante, tuvieron a los liberales como sus más acérrimos rivales. En efecto, Casós pidió la desamortización de los bienes de la Iglesia, mientras que Bambarén planteaba la libertad de culto.

Los debates en el parlamento provocaron incidentes callejeros. Algunos diputados liberales sufrieron agresiones por parte de la población. La muchedumbre pretendía ingresar al Congreso. Producto de esta situación: se realizó la interpelación del "gabinete Tiberiópolis" (conocido así por el título apostólico del obispo, monseñor Pedro José Tordoya, primer ministro y encargado de la cartera de Justicia, Instrucción y Culto). El Parlamento exigió al Ejecutivo una explicación de los hechos, pero tan solo recibió promesas.

El Congreso realizó una votación de censura del gabinete. La censura obtuvo 38 votos a favor y 31 en contra. Por primera vez en la historia del Perú un gabinete ministerial era derribado por el Parlamento. El "gabinete Tiberiópolis" duró tan solo un mes (Elguera, 2002: 706-711). Aprovechando la ocasión, Palma y un grupo de exiliados políticos, abordaron un buque en Guayaquil emprendiendo la vuelta al Perú.

\section{La labor periodística en La Campana}

A su llegada a la capital, Palma se reincorporará a la actividad periodística, formando parte del equipo de redacción de un nuevo periódico político llamado La Campana, de corte satírico 
y de oposición al gobierno de $\operatorname{Prado}^{1}$. Palma será el principal redactor en este periódico y lo acompañarán en la labor periodística destacados hombres de prensa, como Benito Neto, Juan De los Heros y Justiniano de Zubiría. En este periódico ilustrado, con caricaturas de J. J. Rasoir, y otros dibujantes más -similares a los dibujos hechos por otro importante caricaturista del siglo XIX, L. Williez-, Palma escribirá diversos comentarios políticos, exhibiendo como siempre su original e inconfundible lenguaje satírico y zumbón. El primer número de La Campana apareció el domingo 26 de mayo de 1867. Palma, como redactor principal del periódico, llegó a escribir, en la primera página, el editorial titulado "Prospecto que no es prospecto", en donde expresó el afán combativo de la publicación. El siguiente extracto da cuenta de ello:
No hay periódico ni prospecto
como no hay gobierno sin programa aunque hay gobiernos sin ministros
lo cual no carece de gracia ${ }^{2}$.

\begin{abstract}
Asimismo, se dará tiempo en este artículo para dirigir sus críticas hacia el jefe de Estado, por su marcado autoritarismo:
\end{abstract}

I El título de La Campana responde al clima adverso que se vivía en el país, por un decreto del Secretario de Gobierno, José María Químper, de reglamentar los toques de las campanas de las iglesias. En el encabezamiento de esta publicación se puede apreciar una campana y mucho público. Entre las tres personas que tocan la campana se presenta al centro la figura caricaturesca de don Ricardo Palma (larguirucho y de largos y lacios bigotes), mientras las otras dos personas, caricaturizadas igualmente, corresponden a Juan De los Heros y al periodista uruguayo Benito Neto. En la torre del campanario dos personas tienen papeles que reparten a la gente que se encuentra abajo Uno de los hombres que está en el campanario tiene en su mano izquierda un papel que dice: "Policía de cultos". El otro en la misma mano tiene tres papeles donde están escritas las palabras: Bogardus - Timbre - Empréstito Yankee. Abajo está el pueblo cogiendo los papeles escritos desde lo alto.

2 La Campana. $\mathrm{N}^{\circ} 1$. Lima, domingo 26 de mayo de 1867, p.1. 
Cuando al Coronel Prado se le antojó hacernos felices quieras que no quieras, es decir, cuando la proclamación de la dicta-blanda dio programa al yo lo ordeno y cartuchera al fusil y aunque disparato a sus anchas no fueron sus disparates tan gordos como los que vinieron después del 2 de mayo ${ }^{3}$

Precisamente, mientras La Campana continuaba con su labor periodística, el día 3 de junio de 1867 el coronel Mariano Ignacio Prado anunció la noticia de la conformación de un nuevo gabinete presidido por Pedro Paz Soldán y Ureta. Dicho nombramiento será tema de comentario para el propio Palma, quién en el segundo número de La Campana saludó irónicamente tal designación:

Hoy tenemos un Ministerio de gente nueva, flamantita, acabada de nacer: Un Ministerio de pulso, calidad, ñeque, pepodita y remezón ${ }^{4}$.

Por cierto, las críticas en el quincenario no solo eran en prosa; a veces se apelaba a la sátira y la mofa por parte de sus dibujantes. En efecto, el coronel Mariano Ignacio Prado y sus flamantes ministros fueron objeto frecuente de traviesas caricaturas. En el segundo número puede notarse, en una de las páginas, la cabeza del ministro Paz Soldán y Ureta tras un armario vacío, que exhibía un cartelito con la palabra "Hacienda". En el tercer número de La Campana, Palma ensayó el comentario humorístico con estos versos: "se ha lucido ivoto a San / El señor Paz Soldán"5. Mofarse de los Paz Soldán fue un error. Un acto temerario. El poeta de la familia era Juan de Arona, seudónimo de Pedro Paz Soldán y Unanue, hijo del premier

3 Ibídem

4 La Campana. No 2. Lima, domingo 9 de junio de 1867. p.1.

5 La Campana. No 3. Lima, domingo 23 de junio de 1867. p.1. 
Pedro Paz Soldán y Ureta. Ante las críticas de Palma, Arona defendió la honra de su padre y lo atacó por medio de algunas irreverentes sátiras a través de las páginas de El Comercio.

\section{Palma y las Semblanzas}

En efecto, en respuesta a lo vertido en el tercer numero y también por lo expresado en las divertidas semblanzas que hizo Palma -bajo el seudónimo de "Un Campanero"- de los diputados del Congreso Constituyente de 1867, las cuales aparecieron, por primera vez, en el cuarto número de La Campana del 7 de julio de 1867, Arona escribió dos días después, en las paginas de El Comercio, la semblanza del escritor limeño, bajo el título de "Semblanzas. D. Ricardo Palma, Campanero de Cocharcas", en donde lo califica como corrupto, tronchista y tránsfuga traidor. Ante dicha radiografía, que probablemente también debió de incomodarlo, por su alto sentido racista y discriminador, Palma respondió al autor de los Peruanismos -dos días después- con palabras del mismo calibre, a través de una encendida sátira titulada "Mi Semblanza", que sin firma del autor apareció en las paginas de El Comercio:

Pues, señor, es bonita mi semblanza
Y la dejo correr sin desconfianza.
iNo puedo ser un hombre más humilde!
No rechazo ni una coma ni una tilde
Y agrego si se quiere todavía,
Que no es semblanza, que es fotografía

A pesar de los ataques de Arona, Palma no se dejó amilanar, por lo que continuará entreteniendo al público lector con sus simpatiquísimas semblanzas, en donde seguirá retratando, en

6 El Comercio. Lima, 11 de julio de 1867. p. 4. 
forma satírica a los representantes del Congreso Constituyente de $1867^{7}$. En la realización de este trabajo, Palma emplea la misma técnica que había adoptado en sus Semblanzas del Congreso Extraordinario de 1858, que fueron publicadas en la Zamacueca Política. Las Semblanzas de Palma describen, de manera breve, los principales rasgos y actitudes de los diputados de ese Congreso; así puede verse algunos rostros que son eternos en la escena parlamentaria: el diputado que no habla, el que habla demasiado, el que cree saber de todo, el que daría cualquier cosa por ser ministro, el que casi no acude a las sesiones, entre otros rasgos más (Basadre, 2005, VI: 260). Para realizar estas Semblanzas, Palma tuvo que hacerse presente en el recinto parlamentario, lugar en donde pudo observar y escuchar las intervenciones personales de los principales parlamentarios, así como de los acalorados debates de los miembros de la asamblea que, por cierto, tenía una doble función: la primera era legislar y la segunda era elaborar una nueva Constitución Política del Perú. Al parecer, la propuesta de los representantes liberales no le pareció tan convincente en algunos aspectos. Lo único que quizá pudo compartir con ellos, en ese momento, fue su anticlericalismo, el cual se fue forjando como consecuencia de la influencia de intelectuales de la talla de Francisco de Paula Gonzales Vigil y Francisco Javier Mariátegui (Holguín, 2006: 65). No obstante, en otros puntos, el futuro tradicionista debió de mostrarse más inclinado a una postura moderada o conservadora, por lo que irá poco a poco apartándose de algunos principios liberales aprendidos durante su juventud.

7 A fines de julio de 1867, Palma mandó a editar en un folleto sus Semblanzas por un Campanero, que aparecieron en el periódico La Campana (Publicación $\mathrm{N}^{\circ} 4$ y $\mathrm{N}^{\circ} 5$ del 7 y 21 de julio de 1867). En 1961, Alberto Tauro del Pino, reeditó nuevamente el folleto, añadiendo además las semblanzas que hizo el tradicionista de los representantes del Congreso Extraordinario de 1858 las cuales fueron dadas a conocer en el periódico La Zamacueca Política. 
En las Semblanzas de 1858, Palma había enfilado sus ataques a los parlamentarios conservadores, pero, en esta ocasión, varios de los diputados de tendencia liberal serán el principal blanco de sus críticas, siendo por ello inconsecuente con su credo y poco solidario con sus compañeros de bandera ideológica, lo cual será una clara demostración de que su liberalismo político se había vuelto más moderado o conservador como consecuencia del diálogo permanente con los miembros del círculo de confianza de Balta. Un claro ejemplo de esta crítica será con su amigo de "bohemia" y reconocido liberal José Casimiro Ulloa, a quien describirá del siguiente modo:
Liberalismo, predica, predicó y predicará
Más ¿Quién, diablos me explica
como es que siempre está
con frases de botica
(males como el purgante de mamá)
Lo contrario amparando? iCosa rica!
Como escritor liberalismo encaja
más como diputado es pura paja
(Palma, 1961: 35).

El reconocido medico, político liberal y anticlerical Celso Bambarén, diputado por Huaraz, será otro legislador más retratado por la pluma de Palma. Sobre él dirá:

A la verdad que me crispo

Diciendo que este señor tiene tanto de orador

Como tiene de arzobispo.

En un discurso hizo halago

$\mathrm{Al}$ candor de las mujeres;

Y ellas le dieron el pago

Con alfalfa y alfileres.

Entonces él por lo visto 
Se declaro muy formal,

Enemigo personal

De mi señor Jesucristo

(Ibíd.: 34)

Una crítica similar hará también con su compañero de "bohemia" el gran pintor y también escritor Francisco Laso, quien llamándose liberal adoptó una actitud poco consecuente con sus principios liberales en el tema de la reforma religiosa, ya que llegó a votar en contra de la tolerancia de cultos, lo que llevó a Palma a lanzarle una crítica directa en su semblanza:

Fuera preocupación

- nos gritaba desde Francia

Vino a ilustrar la nación

Y luego al primer tapón

Votó por la intolerancia"

(Ibíd.:45).

El doctor Francisco García Calderón, diputado por Arequipa, prestigioso abogado y autor del Diccionario de la Legislación Peruana no pudo escapar de la mofa y el sarcasmo de Palma. Sobre él, Palma dijo lo siguiente:

Lo apellidan Diccionario

Por lo sabio y lo modesto,

Y lo alaba por supuesto

Todito el abecedario.

Además de su hidalguía

Tiene otras prendas que callo

Y solo una falta le hallo.

¿Cuál? Su falta de energía.

(Ibíd.: 36)

Asimismo, un liberal asociado y comprometido con la dictadura de Prado como José María Químper, secretario de Gobierno y 
diputado, será retratado por Palma de un modo nada respetuoso. De él dirá lo siguiente:

\section{Chismes no te son ajenos \\ ¿Y en que farsa no estarás? \\ No hay hombre que suene más \\ No hay hombre que valga menos}

(Ibíd.: 46).

Sin embargo, el diputado liberal de Trujillo, Fernando Casós, una de las figuras más renombradas de este Congreso Constituyente, tuvo la suerte de recibir una benevolente crítica por parte del autor de las Semblanzas:

$$
\begin{aligned}
& \text { Gran orador de verdad } \\
& \text { que hoy anda con paliativos; } \\
& \text { pero dio golpes muy vivos } \\
& \text { a Gobierno... y sociedad } \\
& \text { Cajista, por suspensivo } \\
& \text { (Ibíd.: } 46 \text { ). }
\end{aligned}
$$

Todo lo contrario sucederá con la semblanza hecha al diputado por Cañete, Demetrio de O'Higgins, de quien dirá:

\section{Su señoría es nada \\ Ni chicha ni limonada}

(Ibíd.: 45).

Mas allá de estas jocosas sátiras, La Campana seguirá manteniendo con firmeza su labor opositora contra la dictadura de Prado, lo cual llevó a que sus redactores -que eran cincosean advertidos de una probable detención por parte de la Secretaría de Gobierno. Precisamente, uno de los redactores de La Campana, el colombiano Justiniano de Zubiría, será llevado a prisión días antes de la aparición del quinto número de La 
Campana (domingo 21 de julio de 1867). Al parecer, dicho arresto pudo ser una venganza llevada a cabo por Juan de Arona, quien fue agredido por el periodista colombiano en las afueras de la redacción de El Nacional (diario en el cual escribía Arona), por unos versos satíricos del escritor costumbrista publicados en las paginas de El Comercio. En una nota de la pagina tres de la publicación numero cinco de La Campana aparece un comunicado, escrito probablemente por Palma, titulado: "A última hora", en donde se hace referencia de la noticia del arresto del redactor colombiano. Asimismo, el autor de la nota deja abierta la posibilidad de especular con el presunto autor intelectual de dicho arresto (¿Arona?):

En prensa ya nuestro número, ha sido puesto en prisión Don Justiniano de Zubiría, uno de los cinco redactores de "La Campana" por orden del señor Ministro de Gobierno. Nos abstenemos de hacer por ahora comentarios sobre este ataque a la libertad individual, ni queremos presumir que don Juan de Arona haya empleado la influencia política de su señor padre el Ministro de Hacienda para vengarse de una ofensa que los hombres de honor ventilan en otros terrenos ${ }^{8}$.

Por cierto, la agresión de Zubiría a Juan de Arona pudo también deberse al hecho de defender la honra mancillada de su amigo y compañero de redacción, Ricardo Palma, quien era constantemente criticado por el hijo del ministro de Hacienda 9 . Lo cierto es que los redactores justificaron la agresión al hijo del ministro. En el mencionado número de La Campana aparece

8 La Campana. $\mathrm{N}^{0}$ 5. Lima, domingo 21 de julio de 1867. p. 3.

9 Además de su incesante crítica en "Don Ricardo Palma, Campanero de Cocharcas", Arona le escribió una irreverente sátira en verso titulado "El Tamalero", la cual fue publicada en El Comercio. Lima, domingo 17 de julio de 1867. p. 4, la misma que debió herir su susceptibilidad por su alto tono de insultos y bajezas. 
una nota de redacción con el titulo de "Algunas palabras serias", en cuya vibración se percibe el tono de Palma. Su autor señala algunas de las razones del suceso:

Las Semblanzas de los Diputados, que tanta polvareda han levantado, no puede imparcialmente decirse que envuelven injurias contra la honra de los representantes. [...] Pero gente que no tenía vela en ese entierro se metió a sudar fiebre ajena y a decirnos desvergüenzas indignas....Por eso uno de los campaneros creyó necesario aplicarle el correctivo que merecen los mastines rabiosos. He aquí por qué Juan de Arona recibió una paliza de buena ley, la cual, pues es joven aún, le aprovechará y servirá de escarmiento para no meterse en lo sucesivo en fiestas a las que no es convidado, y para no herir a traición y bajo el anónimo aún a aquellos a quienes da la mano de amigo y que lo han tratado con deferencia ${ }^{10}$.

Además de sus conocidas Semblanzas, Palma llegó a escribir en dicha publicación otros artículos periodísticos. Uno de ellos, será el infaltable "Repique dominical", en donde comentará, desde su punto de vista personal y como hombre de la oposición, los últimos acontecimientos políticos ocurridos en el país. En efecto, en la edición número siete de La Campana, Palma se refirió a la expectativa que tenía la población peruana ante la próxima promulgación de la nueva Constitución, la misma que podría mejorar algunos aspectos de la situación política reinante, en especial la ola de detenciones, arrestos y deportaciones. Como peruano, Palma se mostró confiado en que el nuevo orden constitucional traería paz y estabilidad en esta tierra:

Nosotros tenemos aquí paz octaviana, felicidad y pesetas, con lo que, sea dicho de paso, fuera disparate pedir más a

10 Ibídem. 
la fortuna. El Congreso y el Gobierno están satisfechos el uno del otro.

\author{
Hay felicidad a mantas \\ Y ese consorcio es tan fiel \\ Como es....el de San Miguel \\ Con el que tiene a sus plantas
}

Por lo pronto el Congreso ha dado al Ejecutivo una dedada de miel con acabar de discutir la Constitución y llevarla en camino de promulgarse muy pronto. Acabáramos que ya era tiempo. Es mucha ganga la que vamos a tener viviendo constitucionalmente. Verá usted como tan luego que entremos de lleno en el régimen constitucional van a repetirse las garantías individuales y no se repetirán las prisiones arbitrarias que han tenido lugar estos días con el coronel Gonzales y don Segundo Suarez ${ }^{11}$.

Asimismo, en otro comentario, Palma continuará criticando a la dictadura. El siguiente "repique", que por cierto, fue el último que escribió nuestro afamado escritor en aquella publicación, es una mofa al jefe de Estado por su desempeño político. El tono irónico y sarcástico de la pluma del escritor lo expresa en prosa y en verso, estableciendo su propio sello personal:

\title{
Después que te conocí \\ Todas las cosas me sobran \\ El sol para tener día \\ Abril para tener rosas
}

Lo que canta esta copla va, si Dios no la remedia, a sucederle a nuestro gobernante cuando empiece a entrar en el ajustado camino de la Constitución. Quien nos gobernó año y medio

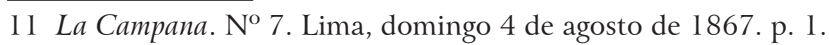


sin más ley que su voluntad soberana, mal podría avenirse a tener que sujetarse a una pauta y a que todo el mundo se crea con derecho a gritarle, cuando quiera sacar los pies del plato: -ialto ahí, compadre, que va usted torcido

\author{
Dictadura! Dictadura \\ Después que te conocí \\ Y me diste tanta holgura \\ ¿Cómo viviré sin ti? ${ }^{12}$.
}

De manera similar que La Campana, otros medios periodísticos también se enfrentaron al régimen de la dictadura. En efecto, por ese mismo año, apareció en Lima un nuevo periódico de oposición llamado El Liberal, cuyo editor y redactor en jefe fue J. L. Torres. Dicha publicación, exhibía en sus páginas algunos versos satíricos que respondían al título de "Chilindrinas". Al parecer, dichos versos, por su singular estilo satírico zumbón, pudieron haber sido también de la autoría de Palma. Precisamente, una de estas "Chilindrinas" alcanzó a criticar al gobierno autoritario del coronel Prado, expresándose del siguiente modo:

El Gobierno paternal

Del gran D. Mariano Ignacio

Busca dinero en palacio

Para hacer un hospital

Pero dicen los amigos

De la ruin maledicencia

¿Por qué mejor Su Excelencia

No suprime a los mendigos?"13.

Tal como podemos observar, el ambiente político peruano para 1867 no era de los mejores. Las críticas y ataques al gobierno

12 La Campana. No 8. Lima, domingo 18 de agosto de 1867. p. 2.

13 El Liberal. N ${ }^{\circ}$ 17. Lima, miércoles 17 de abril de 1867. Sección: "comunicados". 
de Prado y la nueva Constitución, eran motivo de discusión diaria en un gran sector de la población. A ello se le sumaba las serias denuncias contra el sistema consignatario, a raíz de la denuncia hecha, un año antes, por Guillermo Bogardus, en donde se demostraba que las consignaciones representaban grandes pérdidas para el Estado peruano; y también el famoso y discutido empréstito de 1865 con la compañía inglesa Thomson Bonar.

A pesar del complicado momento, La Campana intentó aumentar sus ataques al gobierno, pero las autoridades locales consiguieron poner alto a esta publicación ${ }^{14}$. Palma, consciente de las amenazas del cierre decidió alejarse antes que esto suceda. En efecto, su labor en este periódico será hasta el domingo 18 de agosto, señalando en dicha publicación su alejamiento por causas personales:

Con el presente número cesa la parte que he tenido en la redacción de La Campana; motivos personales que nada tienen de gobiernistas, ni afectan las relaciones de amistad con mis compañeros de redacción, me obligan a dar este paso.

R. P. ${ }^{15}$.

Una vez alejado de La Campana, Palma se tomará un breve descanso en sus actividades políticas. En realidad, debía de reflexionar. Hacer un mea culpa de su participación en el periodismo. Sin embargo, ese descanso no duraría mucho. A fines de ese mes, el día 29 de agosto para ser más exactos, las noticias en torno de la promulgación de la nueva Constitución dieron motivo para una serie de especulaciones por parte de la opinión pública. Algunos se mostraron a favor de esta

14 El último número de La Campana correspondió a la publicación $\mathrm{N}^{\mathrm{o}} 9$ del día 1 de setiembre de 1867.

15 La Campana $\mathrm{N}^{\circ}$ 8. Lima, domingo 18 de agosto de 1867. p. 4. 
Constitución, mientras que otros expresaban su molestia e indignación. Palma, al parecer, debió de estar del lado de los conservadores, por lo que no vio con buenos ojos la mencionada Carta Magna de marcada tendencia liberal.

$\mathrm{Al}$ cabo de unos meses, lo tendremos nuevamente de regreso en una nueva revolución encabezada por su gran amigo José Balta.

\section{Bibliografía}

Basadre Grohman, J. (2005). Historia de la República del Perú (18221933). Lima: Orbis.

Elguera Valega, L. (2002). El conflicto entre el Congreso Constituyente de 1867 y el Gabinete Tiberiópolis en el origen de la eficacia legal del voto de censura en el Perú. Pensamiento Constitucional, Lima: 8, pp. 695-715.

El Comercio. Lima, 11 de julio de 1867. p. 4.

El Liberal. $\mathrm{N}^{\circ}$ 17. Lima, miércoles 17 de abril de 1867.

Gálvez, J. F. (2002). La política como pasión. Breve historia del Congreso de la República (1822-1968). Lima: Fondo Editorial del Congreso del Perú.

Holguín Callo, O. (2006). “Trazos para el perfil religioso de un liberal decimonónico (Ricardo Palma)”. Lima: Revista de la Casa Museo Ricardo Palma, 6, pp. 63-76.

La Campana $\mathrm{N}^{\circ}$ 1. Lima, domingo 26 de mayo de 1867. p. 1

La Campana $\mathrm{N}^{\circ}$ 2. Lima, domingo 9 de junio de 1867. p. 1

La Campana No 3. Lima, domingo 23 de junio de 1867. p. 1 
La Campana No 5. Lima, domingo 21 de julio de 1867. p. 1

La Campana $\mathrm{N}^{\circ}$ 7. Lima, domingo 4 de agosto de 1867. p. 1

La Campana $\mathrm{N}^{\circ}$ 8. Lima, domingo 18 de agosto de 1867. p. 4

Palma, R. (1961). Semblanzas. Edición y prólogo de Alberto Tauro. Lima: Editorial Juan Mejía Baca.

Paz Soldán y Unanue, P. (9 de julio de 1867). "Don Ricardo Palma, campanero de Cocharcas". Lima: El Comercio, p. 5.

Pérez Garay, C. A. (2015). Liberalismo criollo. Ricardo Palma, ideología y política, 1833-1919. Lima: Editorial Universitaria.

Valdizán Ayala, J. (1995). José Balta. Lima: Brasa.

Recibido el 22 de diciembre del 2017 Aceptado el 19 de febrero del 2018 